\title{
Metastasis of Colon Cancer to the Breast
}

\author{
Swei H. Tsung \\ St. Mary's Hospital, Yilan, Taiwan
}

\section{Keywords}

Breast cancer · Metastasis · Colon · Immunohistochemistry

\begin{abstract}
Breast metastases from extramammary neoplasms are extremely rare, and even more so is metastasis of colon cancer to the breast. Despite its rarity, metastatic disease to the breast is an important diagnostic issue because its treatment differs greatly from that of primary cancer. Proper diagnosis of this rare event requires an accurate clinical history, proper immunohistochemical workup, and a high level of suspicion.

\section{Introduction}

The majority of tumors in the breast are primary .Metastatic disease in the breast is an unusual event, and even more so is metastasis of the colon to the breast. Metastatic spread to the breast has an incidence of 0.5 to 3\% from extramammary sites [1].Metastatic tumors in the breast are mostly seen in patients with disseminated malignancies. Occasionally, a breast metastasis may be the first indication of a malignant neoplasm in the breast, and can masquerade clinically as a primary breast tumor. Despite its rarity, metastatic disease to the breast is an important diagnostic concern because its treatment differs greatly from that of primary cancer. Here, a male patient with breast metastasis from colon cancer 2.5 years after colon surgery is presented. 


\section{Case Presentation}

An 82-year-old male visited our outpatient clinic because of a large breast mass noted for several weeks. On physical examination, a tumor measuring $3 \times 3 \times 2 \mathrm{~cm}$ was found in the left breast at the 12 o'clock position, $1 \mathrm{~cm}$ from the nipple. Laboratory data revealed slight anemia, a hemoglobin level of $11.1 \mathrm{~g} / \mathrm{dl}$, and hematocrit 33.3. Biochemical data were within normal limits. He underwent a CT of the chest, which confirmed the clinical impression of a large left breast mass (Fig. 1a).

In addition, multiple nodular lesions were found in the right lung field. The radiological findings were interpreted as primary breast cancer with lung metastasis. The patient underwent core biopsy of the breast mass, and histological examination of the specimen was interpreted as infiltrating ductal carcinoma. Subsequently, he had a simple mastectomy without lymph node dissection.

\section{Histopathology}

The resected specimen consisted of a $10.5 \times 5.9 \times 3.2 \mathrm{~cm}$ oval portion of breast tissue attached with a skin. The cut surface revealed a grayish white, firm tumor with pushing margins, measuring $3.6 \times 2.8 \times 2.6 \mathrm{~cm}$ (Fig. 1b). Histologically, the tumor was composed of malignant glands of various size and shape. The lining cells of the glands were of the tall columnar type, and the lumen often contained necrotic debris (Fig. 1c).

The morphology was the reminiscent of the colon cancer. This observation prompted us to communicate with the surgeon who informed us about the medical history that the patient had colon resection for cancer two and half years ago at the other hospital. In order to prove that the tumor was a metastatic tumor from the colon, we made several immunohistochemical stains. ER, PR, Her2/neu, CK7, CK20, and GATA-3 all were negative. CDX-2 was positive (Fig. 1d), confirming the diagnosis of metastasis from the colon. The patient refused to have the lung biopsy to determine whether the lesion was of metastasis or the second primary.

\section{Discussion}

The first reported case of extramammary breast metastasis occurred in 1903 [2]. In the last century, the majority of reports in the literature were isolated case reports or small series. The largest such collective review was published by Williams et al. [3] from the MD Anderson Cancer Center in Houston, Texas. They described 169 patients over a 15-year time period. The most common primary site was the skin; the gastrointestinal tract ranked fourth $(12 / 169)$. In these 12 patients, the authors did not specify which part of the gastrointestinal tract was the primary site. In 1976, McIntosh et al. [4] reported a case of colon cancer that metastasized to the breast. In 2014, Vakili et al. [5] reported a case and found 22 cases in the literature.

The colon cancer metastasized to the breast can be synchronous or metachronous. On average, breast metastasis was reported to appear 21 months following the diagnosis of colon cancer, with the longest interval being 7 years. Only 3 breast metastases were in men. The majority of metastases $11(55 \%)$ were to the left breast, with the averaged $3.5 \mathrm{~cm}$ in size and ranged from 1 to $11 \mathrm{~cm}$. Histopathology often demonstrated mucinous or signet-ring cell features, unlike our case which showed moderately differentiated adenocarcinoma. 
In patients with a history of colon cancer presenting a palpable breast lump, the clinician should inform the pathologist about the history which could facilitate the correct diagnosis. In our case, the lack of a prior history of colon cancer led to initial misinterpretation by the radiologist and pathologist.

Immunohistochemistry can be very valuable to confirm the primary site being in the colon. According to a study by Bayrak et al. [6], the CK7-/CK20+ phenotype was found in $65.8 \%$ of the patients with colorectal cancer. In our case, both CK7 and CK20 were negative. However, CDX2 was strongly positive. With the given history and negative results in ER, PR, Her2/neu, and Gata-3, we confirmed that the breast mass was of metastasis from colon.

Limited information is available in the literature. According to the recent report, the management of metastatic breast mass from colorectal cancer should be diagnostic and palliative. Barthelmes et al. [7] advocated that surgical excision should be avoided in view of the short life expectancy and risk of seeding to the skin, but in the literature, most breast lumps have been excised. This is understandable if the lump is mistaken for a primary breast cancer as in our case. Oral capecitabine, which was prescribed for palliative chemotherapy, might further slow the growth of the patient's metastasis in the breast [8]. Despite treatment advances over years, the median survivals were in the range of 8-10 months [3]. Our patient was still alive at 6 months follow-up.

\section{Conclusion}

Metastasis to the breast from colon adenocarcinoma is very rare. It can mimic primary breast cancer and must thus be considered in the differential diagnosis of a suspicious breast mass, especially if the patient has a history of cancer. This entity carries a poor prognosis because it is usually indicative of disseminated disease, and local therapy should be individualized. Proper diagnosis of this rare event requires an accurate clinical history, proper immunohistochemical workup, and a high level of suspicion.

\section{Statement of Ethics}

The author has no ethical conflicts to disclose.

\section{Disclosure Statement}

The author has no conflicts of interest to declare.

\section{References}

1 McCrea EA, Johnstone C, Haney PJ: Metastasis to the breast. AJR Am J Roentgenol 1983;141:685-690.

-2 Trevithick E: A case report of chloroma with clinical history and account of post mortem appearances. Lancet 1903;2:158-160.

-3 Williams SA, Ehlers RA 2nd, Hunt KK, Yi M, Kuerer HM, Singlatary SE, Ross MI, Feig BW, Symammans WF, Meric-Bernstam F: Metastases to the breast from nonbreast solid neoplasms: presentation and determinants of survival. Cancer 2007;110:731-737.

4 McIntosh IH, Hooper AA, Millis RR, Greening WP: Metastatic carcinoma within the breast. Clin Oncol 1976;2:393-401. 


\section{Case Reports in Oncology}

\begin{tabular}{l|l}
\hline Case Rep Oncol 2017;10:77-80 \\
\hline DOI: $10.1159 / 000455225$ & $\begin{array}{l}\text { C } 2017 \text { The Author(s). Published by S. Karger AG, Basel } \\
\text { www.karger.com/cro }\end{array}$ \\
\hline
\end{tabular}

Tsung: Metastasis of Colon Cancer to the Breast

5 Vakili SM, Sharbatdaran M, Noorbaran A, Siadati S, Moslemi D, Shafahi S: A case of colon cancer with breast metastasis and Krukenberg tumor. Int J Hematol Oncol Stem Cell Res 2014;8:46-50.

-6 Bayrak R, Yenidünya S, Haltas H: Cytokeratin 7 and cytokeratin 20 expression in colorectal adenocarcinomas. Pathol Res Pract 2011;207:156-160.

-7 Barthelmes L, Simpson JS: Douglas-Jones AG, Sweetland HM: Metastasis of primary colon cancer to the breast - leave well alone. Breast Care (Basel) 2010;5:23-25.

-8 Rossi D, Alessandroni P, Catalano V, Giordani P, Fedeli SL, Fedeli A, Baldelli AM, Casadei V, Ceccolini M, Catalano G: Safety profile and activity of lower capecitabine dose in patients with metastatic breast cancer. Clin Breast Cancer 2007;7:857-860.
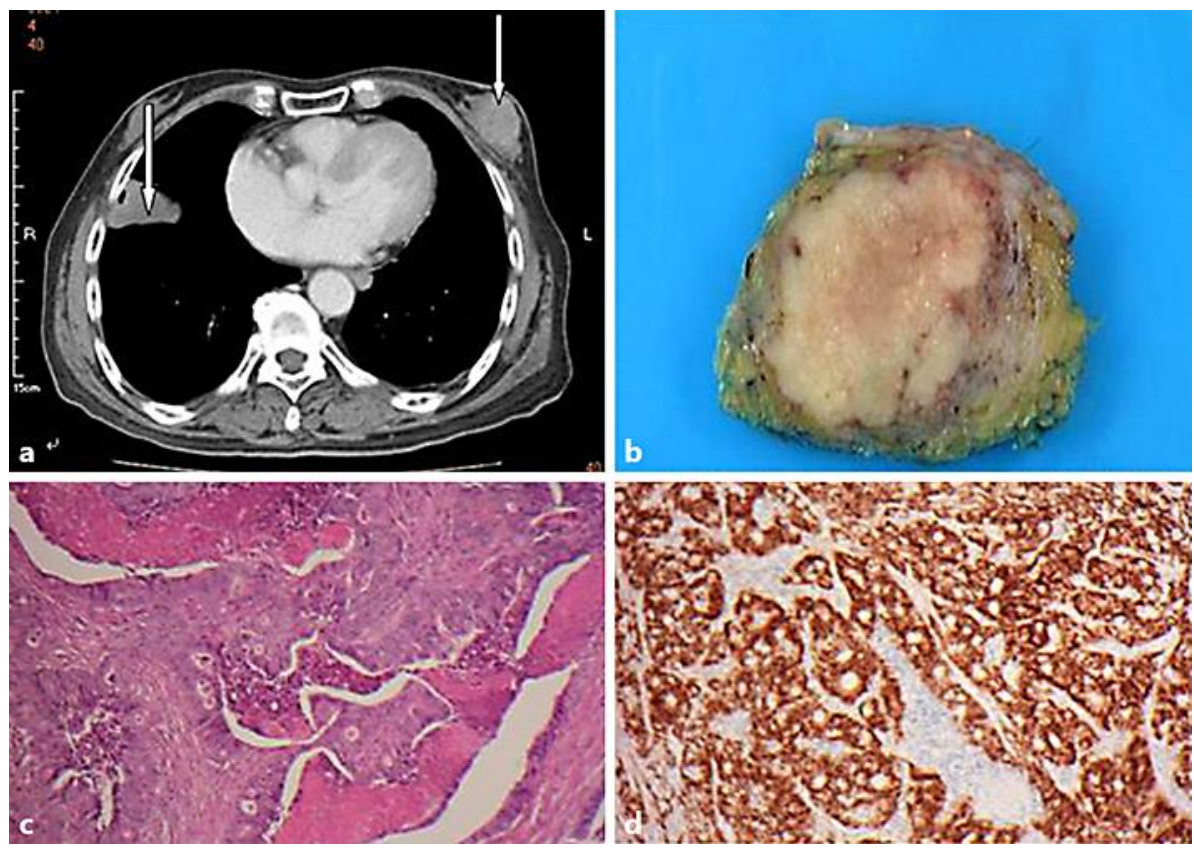

Fig. 1. a CT of the chest demonstrating a soft-tissue mass in the left breast and in the right lung. $\mathbf{b}$ The resected specimen showing a tumor with pushing margins and measuring $3.6 \times 2.8 \times 2.6 \mathrm{~cm}$. c Microscopic sections of the tumor showing malignant glands resembling adenocarcinoma of the colon. HE. $\times 400$. d Positive staining with anti-CDX-2. $\times 200$. 